\title{
Reduction in urinary albumin excretion with a moderate low-carbohydrate diet in patients with type 2 diabetes: a 12-month intervention
}

This article was published in the following Dove Press journal:

Diabetes, Metabolic Syndrome and Obesity:Targets and Therapy

10 August 2012

Number of times this article has been viewed

\author{
Hajime Haimoto' \\ Tae Sasakabe ${ }^{2}$ \\ Hiroyuki Umegaki ${ }^{3}$ \\ Kenji Wakai ${ }^{4}$ \\ 'Department of Internal Medicine, \\ Haimoto Clinic, Kasugai, ${ }^{2}$ Department \\ of Clinical Nutrition, Haimoto Clinic, \\ Kasugai, ${ }^{3}$ Department of Geriatrics, \\ Nagoya University Graduate School \\ of Medicine, Nagoya, ${ }^{4}$ Department \\ of Preventive Medicine, Nagoya \\ University Graduate School of \\ Medicine, Nagoya, Japan
}

Introduction: Urinary albumin excretion (UAE) is a marker of the early phase of diabetic nephropathy. Although a low-carbohydrate diet (LCD) has been shown to effectively improve glycemic control in patients with type 2 diabetes (T2DM), its effects on UAE remain unknown.

Patients and methods: A total of 124 patients (mean age \pm standard deviation, $61.6 \pm 9.2$ years) with T2DM were instructed to consume a moderate LCD $(1734 \pm 416 \mathrm{kcal} / \mathrm{d}$; $\%$ carbohydrate:fat:protein $=38: 37: 19$ ) for 12 months. We measured the levels of UAE, hemoglobin $\mathrm{A}_{1 \mathrm{c}}$, fasting plasma glucose, fasting serum insulin (IRI), and the serum lipid profiles in the patients and recorded their dosages of antidiabetic drugs during this 12-month period. Results: Of the 124 patients, 68 were normoalbuminuric, 50 were microalbuminuric, and six were macroalbuminuric at baseline. The patients had relatively good compliance with the moderate LCD diet. After 12 months, the mean levels of hemoglobin $\mathrm{A}_{1 \mathrm{c}}$, fasting plasma glucose, IRI, homeostasis model assessment-estimated insulin resistance, and the body mass index of all participants significantly decreased ( $P=0.003$ for IRI and $P<0.001$ for the other parameters). Among the microalbuminuric patients $(n=50)$, remission to normoalbuminuria was frequently achieved (52\%) and the geometric mean UAE significantly decreased by 53\% (95\% confidence interval: 43,62) over 12 months $(P<0.001)$. After patients taking an angiotensin 2 receptor blocker were excluded, the UAE significantly decreased by $41 \%(\mathrm{n}=26,95 \%$ confidence interval: 25,$54 ; P<0.001$ ). Moreover, the reduction in UAE was significantly and positively correlated with a reduction in homeostasis model assessment-estimated insulin resistance levels $\left(\mathrm{r}_{\mathrm{s}}=0.308 ; P=0.031\right)$.

Conclusion: A moderate LCD (38\% carbohydrate diet) achieved a remarkable reduction in UAE over 12 months in microalbuminuric patients with T2DM.

Keywords: glycemic control, microalbuminuria, angiotensin 2 receptor blockers, insulin resistance

\section{Introduction}

Diabetic nephropathy develops in approximately $20 \%$ to $40 \%$ of patients with type 2 diabetes (T2DM) and is the leading cause of end-stage renal disease. ${ }^{1-3}$ Urinary albumin excretion (UAE) is a marker of early phase diabetic nephropathy and endothelial damage. ${ }^{1-5} \mathrm{~A}$ gradual increase in microalbuminuria results in progression to macroalbuminuria and a rapid decline in renal function. A decrease in UAE is associated with a lower risk of cardiovascular and renal events in T2DM patients. ${ }^{1,2,4,5}$ Therefore, early intervention to decrease UAE may prevent the development of microalbuminuria and the progression of existing microalbuminuria; early intervention may also result in the remission of existing albuminuria. ${ }^{1-5}$
Correspondence: Hajime Haimoto Haimoto Clinic, I-80 Yayoi, Kasugai, Aichi 486-0838, Japan

Tel $+8 I 568858226$

Fax +8I 568858315

Email haimoto@gol.com 
The available therapeutic strategies for the management of UAE include measures to control glucose levels and hypertension and the treatment of dyslipidemia. ${ }^{1,2,4,5}$ Under high-carbohydrate conditions, intensive glycemic control using insulin and/or sulfonylureas for 6 to 8 years prevents progression from microalbuminuria to macroalbuminuria more efficiently than conventional therapy. ${ }^{1,4,6}$ Moreover, angiotensin-converting enzyme (ACE) inhibitors and angiotensin 2 receptor blockers (ARBs) have been shown to reduce albuminuria in patients with T2DM. ${ }^{2,4,7}$

Low-carbohydrate diets (LCDs) are more effective than high-carbohydrate diets (HCDs) at improving glycemic control among patients with T2DM. ${ }^{8,9}$ Because LCDs increase serum high-density lipoprotein (HDL) cholesterol level and decrease both body weight and serum triglyceride level, ${ }^{10}$ LCDs are more effective in the management of cardiovascular risk factors than HCDs among patients with T2DM..$^{9-11}$ Compared with Western populations, the proportion of energy derived from carbohydrates in East Asian populations is generally higher (approximately 60\%) and the fat proportion is generally lower (approximately 25\%). ${ }^{12,13}$ Therefore, compared with HCDs, moderate, nonketogenic LCDs (but not ketogenic LCDs) may be sufficiently effective for glycemic control in East Asian patients with T2DM. The carbohydratereduced diet (CARD), a moderate $\mathrm{LCD}$, has been shown to effectively reduce weight and hemoglobin $\mathrm{A}_{1 \mathrm{c}}\left(\mathrm{HbA}_{1 \mathrm{c}}\right)$ levels and to improve serum lipid profiles in Japanese patients with mild or severe T2DM. ${ }^{14-16}$ Recently, moderate LCDs have attracted growing interest for the management of cardiovascular risk factors in patients with T2DM, owing to the possible increases in mortality from cancer and unspecified causes that have been associated with stricter carbohydrate restriction in studies carried out over the past 20 years. ${ }^{17,18}$

Although LCDs have a potential role in the management of T2DM, the effects of LCDs on UAE have not yet been characterized. Therefore, we conducted the present study with the following aims: to assess the effects of a moderate LCD on changes in UAE in T2DM patients over 12 months and to elucidate the changes in cardiovascular risk factors that accompany the changes in UAE in microalbuminuric patients.

\section{Patients and methods}

\section{Patients}

Between January 2008 and July 2010, we invited all new Haimoto Clinic T2DM outpatients with $\mathrm{HbA}_{1 \mathrm{c}}$ levels of $6.5 \%$ or above to participate in this study. All patients met the National Diabetes Data Group criteria for T2DM. ${ }^{3}$ The patients were seen at the outpatient clinic every month.
Patients with serum creatinine $(\mathrm{Cr})$ levels greater than $1.5 \mathrm{mg} / \mathrm{dL}$, severe diabetes complications (eg, proliferative retinopathy, symptomatic neuropathy, or diabetic foot syndrome), ketoacidosis, soft-drink ketosis, ${ }^{19}$ cancer, severe heart failure, or liver cirrhosis, were excluded. Of the 144 eligible Japanese patients, 134 participated in the study; ten refused to take part because they did not accept carbohydrate restriction or the dietary treatment. During the study period, seven patients were voluntarily lost to follow-up and three relocated, leaving 124 for the analyses (62 men and 62 women; age: mean \pm standard deviation $=62 \pm 9$ years, range: $34-83$ years).

The protocol for the present study was identical to the protocols of previous studies ${ }^{14,15}$ and as approved by the Ethical Committee of the Nagoya Tokushukai General Hospital (approval number: 07-10-102). All patients provided written informed consent, and the study was performed in accordance with the Declaration of Helsinki.

\section{Moderate LCD}

The main principle of the CARD is to eliminate carbohydrate-rich food (the list of these foods has been reported elsewhere $)^{14,15}$ once or twice daily, at breakfast and/ or dinner. ${ }^{14}$ The target dietary percentage of energy derived from carbohydrates $(\% \mathrm{C})$ was $30 \%-40 \%$. Patients with $\mathrm{HbA}_{1 \mathrm{c}}$ levels $<9 \%$ were instructed to eliminate carbohydrate-rich food at dinner (less strict CARD), whereas those with levels $\geq 9 \%$ were instructed to eliminate it at both dinner and breakfast (strict CARD). All patients were forbidden to consume carbohydrate-containing foods between meals, but were permitted to eat as much protein and fat, including saturated fats, as they wished. There were no other restrictions. These protocols made it easier for our diabetic outpatients to successfully implement the diets.

The patients had not consumed LCDs before this intervention. An experienced dietician performed all of the dietary assessments and gave instructions to all of the participants three times during the first month and once per month thereafter. At the midpoint of the study period, the patients' dietary intake was assessed based on 3-day dietary records.

The patients were requested to maintain their usual level of physical activity throughout the study. Changes in activity levels were evaluated using a questionnaire.

\section{Clinical assessment}

We measured the body mass index (BMI), blood pressure (BP), and the $\mathrm{HbA}_{1 \mathrm{c}}$ level of each patient every month. As soon as the $\mathrm{HbA}_{1 \mathrm{c}}$ levels of the patients were controlled, 
we decreased the dosage of sulfonylureas and prescribed metformin or acarbose in place of the sulfonylureas.

Fasting plasma glucose (FPG), fasting serum insulin (IRI), triglycerides, low-density lipoprotein cholesterol, HDL cholesterol, and $\mathrm{Cr}$ levels were obtained from venous blood samples after an overnight (12-hour) fast every 6 months.

The urinary albumin concentration was determined at baseline and after 12 months (the end of the study). For each measurement, a spot urine sample was collected after overnight fasting on two separate occasions, ${ }^{3}$ and the mean UAE value of the two samples was used for statistical analysis, at the baseline and at the end of the study. Normoalbuminuria, microalbuminuria, and macroalbuminuria were defined as UAE levels $<30 \mathrm{mg} / \mathrm{g} \mathrm{Cr}, 30-299 \mathrm{mg} / \mathrm{g} \mathrm{Cr}$, and $\geq 300 \mathrm{mg} / \mathrm{g}$ $\mathrm{Cr}$, respectively.

Hypertension was defined as a BP $\geq 140 / 90 \mathrm{mmHg}$ and/or the use of antihypertensive therapy at baseline. The target BP was 135/85 $\mathrm{mmHg}$ because at the time of study, these BP values had been shown to slow the progression of renal diseases in T2DM patients. ${ }^{20} \mathrm{~A}$ low dose of olmesartan ( 5 or $10 \mathrm{mg} / \mathrm{d}$ ), an ARB, in combination with indapamide $(0.5$ or $1.0 \mathrm{mg} / \mathrm{d})$ was primarily used for the treatment of hypertension because the use of ARBs in such combinations improves renal outcomes in subjects with hypertension and T2DM. ${ }^{21}$ If the patient's BP did not reach the optimal value, other classes of antihypertensive drugs, including calcium channel blockers and/or guanabenz, were added.

The doses of all antihypertensive, lipid-lowering, or antidiabetic drugs (glibenclamide, gliclazide, glimepiride, tolbutamide, metformin, nateglinide, pioglitazone, voglibose, sitagliptin, and insulin) taken by the patients were also recorded.

\section{Laboratory methods}

Plasma glucose concentrations were determined using enzymatic methods (QUICKAUTONEO GLU-HK, Shino-Test Co, Kanagawa, Japan). Serum insulin levels were measured using the standard double antibody radioimmunoassay method (LUMIPULSE Prestoinsulin, Fujirebio Inc, Tokyo, Japan). Serum and urinary $\mathrm{Cr}$ and triglyceride concentrations were measured using enzymatic methods (PUREAUTOS CRE-L and PUREAUTOS TG-N, Daiichi Pure Chemicals Co, Tokyo, Japan). Serum low-density lipoprotein cholesterol and HDL cholesterol levels were assayed using direct methods (Cholestest LDL and CholestestN HD, Daiichi Pure Chemicals Co). The $\mathrm{HbA}_{1 \mathrm{c}}$ levels were measured by high-performance liquid chromatography (ADAMS A1c HA-8170, Arkley Co, Kyoto, Japan). The UAE was measured using an immunoturbidimetric assay (JCA-BM8000, Nihon Denshi, Tokyo, Japan).

\section{Statistical analysis}

The parameter change $(\Delta)$ for each biomarker was defined as the level after 12 months minus the level at baseline. All the values except UAE are expressed as the mean \pm standard deviation. The UAE was logarithmically transformed before analysis because of its skewed distribution and is reported as the geometric mean ( $95 \%$ confidence interval [CI]). The homeostasis model assessment of insulin resistance (HOMA-IR) parameter was computed as follows: ([FPG $(\mathrm{mg} / \mathrm{dL})] \times[$ fasting serum insulin $(\mu \mathrm{IU} / \mathrm{mL})]) / 405 .{ }^{22}$ The estimated glomerular filtration rate (eGFR) was computed using a previously described equation, with modifications for Japanese subjects. ${ }^{23}$

The Wilcoxon test was used to assess the changes in each parameter (except for UAE) caused by the moderate LCD, comparing the baselines with the levels after 12 months for all patients. The paired $t$-test was used to assess changes in UAE.

The Mann-Whitney test was additionally applied to compare the baseline levels of each biomarker in the normoalbuminuric and microalbuminuric patients. Moreover, the test was used to compare macronutrients and changes in biomarker levels in patients on less strict CARD and those on strict CARD.

We computed Spearman's correlation coefficients $\left(r_{s}\right)$ to examine the correlation of the UAE percentage change $(\Delta \%$ UAE) with changes in cardiovascular risk factors.

$P$ values $<0.05$ were considered statistically significant. All statistical analyses were performed using SPSS (v 15.0; SPSS, Inc, Chicago, IL).

\section{Results}

Effects of the moderate LCD on glycemic control and cardiovascular risk factors

The baseline characteristics of the 124 patients are shown in Table 1. Interestingly, there were no significant differences between the analyzed patients and the 20 eligible patients excluded from study. The baseline characteristics of the excluded patients were $60.9 \pm 11.2$ years of age, $25.6 \pm 3.8$ BMI, $7.9 \% \pm 1.1 \% \mathrm{HbA}_{1 \mathrm{c}}$ levels, and $3.1 \pm 2.4$ HOMA-IR. Of these 20 patients, $14(70 \%)$ were normoalbuminuric, five $(25 \%)$ were microalbuminuric, and one $(5 \%)$ was macroalbuminuric at baseline.

Compared with the baseline values, the mean $\mathrm{HbA}_{1 \mathrm{c}}$ and FPG levels and the mean BMI significantly decreased after 12 months, from $7.9 \% \pm 1.5 \%$ to $6.7 \% \pm 0.6 \%, 151 \pm 48 \mathrm{mg} / \mathrm{dL}$ to $130 \pm 27 \mathrm{mg} / \mathrm{dL}$, and $24.3 \pm 3.7$ to $23.5 \pm 3.7$, respectively $(P<0.001$ for all parameters) (Table 1$)$. The levels of other cardiovascular risk factors, such as IRI, HOMA-IR, and 
Table I Body mass index, glycemic control, serum lipid profiles, blood pressure, and drugs at baseline and 12 months in all patients $(n=124)$

\begin{tabular}{|c|c|c|c|}
\hline & Baseline & At 12 months & $P^{*}$ \\
\hline Body mass index & $24.3 \pm 3.7$ & $23.5 \pm 3.7$ & $<0.001$ \\
\hline $\begin{array}{l}\text { Fasting plasma glucose } \\
(\mathrm{mg} / \mathrm{dL})\end{array}$ & $|5| \pm 48$ & $130 \pm 27$ & $<0.001$ \\
\hline Hemoglobin $A_{l c}(\%)$ & $7.9 \pm 1.5$ & $6.7 \pm 0.6$ & $<0.001$ \\
\hline Fasting insulin $(\mathrm{IU} / \mathrm{mL})$ & $7.6 \pm 5.1$ & $6.8 \pm 4.9$ & 0.003 \\
\hline HOMA-IR & $2.9 \pm 2.3$ & $2.2 \pm 1.8$ & $<0.001$ \\
\hline LDL-cholesterol $(\mathrm{mg} / \mathrm{dL})^{\dagger}$ & $|3| \pm 3 \mid$ & $125 \pm 27$ & 0.126 \\
\hline HDL-cholesterol $(\mathrm{mg} / \mathrm{dL})^{\dagger}$ & $56 \pm 15$ & $61 \pm 18$ & 0.001 \\
\hline Triglycerides $(\mathrm{mg} / \mathrm{dL})^{\dagger}$ & $125 \pm 109$ & $108 \pm 72$ & 0.323 \\
\hline $\begin{array}{l}\text { Systolic blood } \\
\text { pressure }(\mathrm{mmHg})\end{array}$ & $138 \pm 16$ & $132 \pm 14$ & $<0.00$ I \\
\hline $\begin{array}{l}\text { Diastolic blood } \\
\text { pressure }(\mathrm{mmHg})\end{array}$ & $82 \pm 12$ & $79 \pm 9$ & 0.002 \\
\hline eGFR $\left(\mathrm{mL} / \mathrm{min} / \mathrm{l} .73 \mathrm{~m}^{2}\right)$ & $82 \pm 11$ & $81 \pm 22$ & 0.343 \\
\hline Lipid lowering drugs (n) & 30 & 34 & \\
\hline Antihypertensive drugs ( $n$ ) & 47 & 60 & \\
\hline Antidiabetic drugs (n) & 45 & 49 & \\
\hline Glibenclamide & $8 \%(3.1 \mathrm{mg})$ & $2 \%(1.7 \mathrm{mg})$ & \\
\hline Gliclazide & $2 \%(80 \mathrm{mg})$ & $2 \%(25 \mathrm{mg})$ & \\
\hline Glimepiride & $19 \%(2.6 \mathrm{mg})$ & $18 \%(1.1 \mathrm{mg})$ & \\
\hline Nateglinide & $2 \%(180 \mathrm{mg})$ & $0 \%$ & \\
\hline Metformin & $6 \%(568 \mathrm{mg})$ & $20 \%$ (680 mg) & \\
\hline Pioglitazone & I I\% (25 mg) & $3 \%(26 \mathrm{mg})$ & \\
\hline Voglibose & $19 \%(0.8 \mathrm{mg})$ & $6 \%(0.6 \mathrm{mg})$ & \\
\hline Sitagliptin & $0 \%$ & I\% (50 mg) & \\
\hline Insulin & $1 \%(17 \mu)$ & $3 \%(15 \mu)$ & \\
\hline
\end{tabular}

Notes: Data is shown as mean \pm SD. *Wilcoxon test between baseline and 12 months; ${ }^{\dagger}$ patients who received lipid-lowering drugs were excluded $(n=39)$. The percentages indicate the proportion of patients that were prescribed each drug. Values in parentheses are the mean daily doses per person for antidiabetic drugs. Abbreviations: HOMA-IR, homeostasis model of assessment of insulin resistance; LDL, low-density lipoprotein; HDL, high-density lipoprotein; eGFR, estimated glomerular filtration rate; SD, standard deviation.

serum HDL cholesterol significantly improved $(P=0.003$, $P<0.001, P=0.001$, respectively) among the patients treated with CARD for 12 months (Table 1).

At baseline, 44 of the 124 patients (35\%) had already been prescribed antidiabetic drugs by other physicians. By the end of the study, 49 (40\%) patients were taking antidiabetic drugs and these patients were typically prescribed a low dose of metformin and/or glimepiride (Table 1).

The number of patients taking metformin and the dosage of metformin both increased during the study period (Table 1). After excluding patients taking metformin, the mean $\mathrm{HbA}_{1 \mathrm{c}}$ and FPG levels and the mean BMI and HOMA-IR significantly decreased ( $\mathrm{n}=99, P<0.001$ for all).

The number of patients on antidiabetic drugs apart from metformin, and/or the doses of these drugs taken, consistently decreased during the 12-month study period (Table 1). The proportion of patients on sulfonylureas decreased (for glibenclamide and nateglinide) or did not change (for gliclazide and glimepiride) during the 12-month study period and the mean daily dose of sulfonylureas per person tapered off. Three patients required a low dose of insulin therapy to achieve $\mathrm{HbA}_{1 \mathrm{c}}$ levels of less than $6.5 \%$.

Physical activity levels in two female patients (one normoalbuminuric patient and one microalbuminuric patient) increased during the study period despite our instructions; their increase in physical activity was no more than 1 hour of walking per day, 7 days per week, and 40 minutes of walking per day, 3 days per week, respectively.

\section{Baseline characteristics of the normoalbuminuric, microalbuminuric, and macroalbuminuric patients}

Of the 124 patients, 68 (55\%) were normoalbuminuric, $50(40 \%)$ were microalbuminuric, and six (5\%) were macroalbuminuric at baseline (Table 2). The mean baseline UAE levels in the normoalbuminuric, microalbuminuric, and macroalbuminuric patients were $11 \mathrm{mg} / \mathrm{g} \mathrm{Cr}$ (95\% CI: 3, 47), $67 \mathrm{mg} / \mathrm{g} \mathrm{Cr}(56,80)$, and $945 \mathrm{mg} / \mathrm{g} \mathrm{Cr}(234,3802)$, respectively. The $\mathrm{HbA}_{1 \mathrm{c}}$ and FPG levels were significantly higher in the microalbuminuric patients than in the normoalbuminuric patients (Table 2).

\section{Dietary assessment}

The patients showed relatively good compliance with the moderate LCD. The average total daily energy intake was $1734 \pm 416 \mathrm{kcal} / \mathrm{d}$ (Table 3), and the average total daily energy intake per unit body weight was $28.4 \pm 7.1 \mathrm{kcal} / \mathrm{kg} / \mathrm{d}$. The average daily intakes of carbohydrate, fat, and protein were $165 \pm 51 \mathrm{~g}(38 \% \pm 11 \%$ of total energy intake), $72 \pm 30 \mathrm{~g}(37 \% \pm 11 \%$ of total energy intake), and $81 \pm 24 \mathrm{~g}(19 \% \pm 4 \%$ of total energy intake), respectively (Table 3$)$. The carbohydrates were mainly derived from rice $(153 \pm 97 \mathrm{~g})$ and noodles $(54 \pm 68 \mathrm{~g})$ made from wheat or buckwheat. Other carbohydrate sources included potatoes $(19 \pm 32 \mathrm{~g})$, fruits $(60 \pm 80 \mathrm{~g})$, bread ( $31 \pm 35 \mathrm{~g})$, confections ( $17 \pm 24 \mathrm{~g})$, and sugar $(5 \pm 6 \mathrm{~g})$. The mean daily fiber intake was $14 \pm 8 \mathrm{~g}$.

Patients instructed to follow the less strict CARD regimen ( $\mathrm{n}=101)$, whose baseline $\mathrm{HbA}_{1 \mathrm{c}}$ levels were $<9.0 \%$, consumed a diet of approximately $40 \%$ carbohydrate and $36 \%$ fat; whereas patients instructed to follow the strict CARD regimen $(n=23)$, whose baseline $\mathrm{HbA}_{1 \mathrm{c}}$ levels were $\geq 9.0 \%$, consumed a diet of approximately $33 \%$ carbohydrate and $42 \%$ fat (Table 3 ). There were significant 
Table 2 Baseline characteristics of patients by level of UAE $(n=124)$

\begin{tabular}{|c|c|c|c|c|}
\hline & $\begin{array}{l}\text { Normoalbuminuria } \\
(n=68)\end{array}$ & $\begin{array}{l}\text { Microalbuminuria } \\
(n=50)\end{array}$ & P* & $\begin{array}{l}\text { Macroalbuminuria } \\
(n=6)\end{array}$ \\
\hline Age (years) & $61 \pm 9$ & $63 \pm 10$ & 0.253 & $66 \pm 9$ \\
\hline Sex (male/female) & $38 / 30$ & $21 / 29$ & & $3 / 3$ \\
\hline Duration of diabetes (months) & $57 \pm 83$ & $79 \pm 99$ & 0.590 & $124 \pm 49$ \\
\hline Body mass index & $24.3 \pm 3.8$ & $24.2 \pm 4.0$ & 0.957 & $23.6 \pm 2.1$ \\
\hline Fasting plasma glucose (mg/dL) & $135 \pm 36$ & $168 \pm 54$ & $<0.001$ & $182 \pm 54$ \\
\hline Hemoglobin $\mathrm{A}_{\mathrm{kc}}(\%)$ & $7.6 \pm 1.4$ & $8.3 \pm 1.6$ & 0.015 & $8.5 \pm 2.3$ \\
\hline Fasting serum insulin (IU/mL) & $7.7 \pm 4.9$ & $7.8 \pm 5.5$ & 0.858 & $4.6 \pm 1.9$ \\
\hline HOMA-IR & $2.6 \pm 2.0$ & $3.3 \pm 2.7$ & 0.252 & $2.0 \pm 0.9$ \\
\hline LDL-cholesterol $(\mathrm{mg} / \mathrm{dL})^{\dagger}$ & $132 \pm 29$ & $128 \pm 35$ & 0.200 & $157 \pm 57$ \\
\hline HDL-cholesterol $(\mathrm{mg} / \mathrm{dL})^{\dagger}$ & $55 \pm 13$ & $59 \pm 18$ & 0.300 & $54 \pm 14$ \\
\hline Triglycerides $(\mathrm{mg} / \mathrm{dL})^{\dagger}$ & $113 \pm 76$ & $143 \pm 146$ & 0.504 & $200 \pm|3|$ \\
\hline Systolic blood pressure (mmHg) & $134 \pm 15$ & $141 \pm 16$ & 0.086 & $152 \pm 21$ \\
\hline Diastolic blood pressure $(\mathrm{mmHg})$ & $81 \pm 12$ & $81 \pm 11$ & 0.937 & $85 \pm 3$ \\
\hline UAE (mg/g Cr) $(95 \% \mathrm{Cl})^{\ddagger}$ & II $(3,47)$ & $67(56,80)$ & $<0.001$ & $945(234,3802)$ \\
\hline $\mathrm{eGFR}\left(\mathrm{mL} / \mathrm{min} / 1.73 \mathrm{~m}^{2}\right)$ & $84 \pm 20$ & $81 \pm 21$ & 0.601 & $71 \pm 37$ \\
\hline Antihypertensive drugs (\%) & $47 \%$ & $46 \%$ & & $83 \%$ \\
\hline Olmesartan & $43 \%$ & $46 \%$ & & $83 \%$ \\
\hline Indapamide & $43 \%$ & $46 \%$ & & $66 \%$ \\
\hline Calcium channel blockers & $15 \%$ & $14 \%$ & & $33 \%$ \\
\hline Guanabenz & $7 \%$ & $2 \%$ & & $17 \%$ \\
\hline
\end{tabular}

Notes: Data is shown as mean \pm SD. $* P$ between normoalbuminuric and microalbuminuric patients; ${ }^{\dagger}$ patients who received anti-lipid drugs at baseline were excluded $(n=30)$; $\ddagger$ geometric means. The percentages for antihypertensive drugs indicate the proportion of patients who were prescribed each drug.

Abbreviations: $\mathrm{Cr}$, creatinine; UAE, urinary albumin excretion; HOMA-IR, homeostasis model of assessment of insulin resistance; LDL, low-density lipoprotein; HDL, highdensity lipoprotein; $\mathrm{Cl}$, confidence interval; eGFR, estimated glomerular filtration rate; SD, standard deviation.

differences in dietary $\% \mathrm{C}(P=0.010)$ and dietary percentage of energy from fat $(\% \mathrm{~F})(P=0.006)$ between the patients on the less strict CARD regimen and the patients on the strict CARD regimen (Table 3). The strict CARD regimen was associated with significant decreases in FPG concentrations $(-66 \pm 50 \mathrm{vs}-10 \pm 35 \mathrm{mg} / \mathrm{dL}, P<0.001)$, $\mathrm{HbA}_{1 \mathrm{c}}$ levels $(-3.6 \pm 1.4 \mathrm{vs}-0.7 \% \pm 0.7 \%, P<0.001)$, and HOMA-IR $(-1.6 \pm 2.7$ vs $-0.4 \pm 1.3, P=0.001)$, compared with the less strict CARD regimen (Table 3).

\section{Changes in UAE, eGFR, and other cardiovascular risk factors in the normoalbuminuric patients}

In the group of patients with normoalbuminuria, two patients (3\%) progressed to microalbuminuria over the course of 1 year (Figure 1). One patient was an 83-year-old female with an 84-month history of diabetes, microhematuria, hypertension, and hyperlipidemia. The other patient was a newly diagnosed 51-year-old female with hypertension, hyperlipidemia, and rheumatoid arthritis, who was treated with prednisolone and methotrexate.

The UAE significantly decreased by $20 \%$ (95\% CI: $4,33)$ during the 1 -year study period $(P=0.021)$ (Table 4$)$. The values for BMI, FPG, $\mathrm{HbA}_{1 c}$, IRI, HOMA-IR, serum HDL cholesterol, and systolic and diastolic BP, significantly decreased after 12 months in the normoalbuminuric patients (Table 4). The eGFR did not materially decrease.

\section{Changes in UAE and other cardiovascular risk factors in the microalbuminuric and macroalbuminuric patients}

Among the 50 patients with microalbuminuria, 26 (52\%) underwent remission to normoalbuminuria during the follow-up period (Figure 1). In contrast, one female patient $(2 \%)$ progressed to macroalbuminuria. This patient was 68 years old and had hypertension, hyperlipidemia, and Wegener granulomatosis disease, and was treated with prednisolone.

The UAE significantly decreased in microalbuminuric by $53 \%(95 \%$ CI: 43,62$)$ during the 12 -month study period $(P<0.001)$ (Table 4); the UAE decreased most (by $64 \%$ [95\% CI: 51, 74]) in the hypertensive patients receiving olmesartan $(n=24)$. When patients taking olmesartan were excluded from consideration, the UAE still significantly decreased by $41 \%(\mathrm{n}=26,95 \% \mathrm{CI}: 25,54, P<0.001)$ and when patients taking either olmesartan or metformin were excluded, UAE significantly decreased by $40 \%$ ( $n=24,95 \%$ CI: $22,54, P=0.001)$. No significant difference was found between patients following less strict CARD $(n=35)(53 \%$, 95\% CI: 47, 64) and the patients following strict CARD $(\mathrm{n}=15)(55 \%, 95 \% \mathrm{CI}: 46,68)(P=0.89)$. 
Table 3 Differences of dietary assessment, $\mathrm{BMI}, \mathrm{HbA}_{1 \mathrm{c}}$, and HOMA-IR in less strict and strict CARD patients

\begin{tabular}{|c|c|c|c|}
\hline & $\begin{array}{l}\text { Patients on less } \\
\text { strict CARD* }\end{array}$ & $\begin{array}{l}\text { Patients on strict } \\
\text { CARD* }\end{array}$ & $\mathbf{P}^{\dagger}$ \\
\hline$N$ & 101 & 23 & \\
\hline Male/female & $50 / 51$ & $12 / \mid 1$ & \\
\hline $\begin{array}{l}\text { Normoalbuminuria/ } \\
\text { microalbuminuria (n) }\end{array}$ & $61 / 35$ & $7 / 15$ & \\
\hline Age (years) & $62 \pm 9$ & $59 \pm 9$ & 0.084 \\
\hline $\begin{array}{l}\text { Total energy intake } \\
\text { (kcal/day) }\end{array}$ & $1716 \pm 406$ & $1770 \pm 445$ & 0.60 \\
\hline $\begin{array}{l}\text { Carbohydrate } \\
\text { intake/day (g) }\end{array}$ & $|70 \pm 5|$ & $143 \pm 43$ & 0.012 \\
\hline$\%$ carbohydrate & $40.2 \pm 10.0$ & $32.8 \pm 9.0$ & 0.010 \\
\hline Fat intake/day (g) & $70 \pm 29$ & $84 \pm 32$ & 0.056 \\
\hline$\%$ fat & $36.2 \pm 9.7$ & $42.3 \pm 8.8$ & 0.006 \\
\hline $\begin{array}{l}\text { Protein intake/ } \\
\text { day }(\mathrm{g})\end{array}$ & $80 \pm 22$ & $90 \pm 27$ & 0.010 \\
\hline$\%$ protein & $18.8 \pm 3.9$ & $20.3 \pm 2.9$ & 0.046 \\
\hline $\begin{array}{l}\text { Baseline body } \\
\text { mass index }\end{array}$ & $24.2 \pm 3.9$ & $24.4 \pm 3.4$ & 0.69 \\
\hline $\begin{array}{l}\text { Baseline fasting } \\
\text { plasma glucose } \\
(\mathrm{mg} / \mathrm{dL})\end{array}$ & $138 \pm 35$ & $208 \pm 53$ & $<0.001$ \\
\hline $\begin{array}{l}\text { Baseline hemoglobin } \\
A_{\text {lc }}(\%)\end{array}$ & $7.3 \pm 0.7$ & $10.6 \pm 1.2$ & $<0.001$ \\
\hline Baseline HOMA-IR & $2.5 \pm 1.8$ & $4.4 \pm 3.5$ & 0.011 \\
\hline$\Delta$ body mass index & $-0.8 \pm 1.3$ & $-0.6 \pm 1.2$ & 0.54 \\
\hline $\begin{array}{l}\Delta \text { fasting plasma } \\
\text { glucose }(\mathrm{mg} / \mathrm{dL})\end{array}$ & $-10 \pm 35$ & $-66 \pm 50$ & $<0.001$ \\
\hline $\begin{array}{l}\Delta \text { hemoglobin } \\
\mathrm{A}_{\mathrm{lc}}(\%)\end{array}$ & $-0.7 \pm 0.7$ & $-3.6 \pm 1.4$ & $<0.001$ \\
\hline$\Delta$ HOMA-IR & $-0.4 \pm 1.3$ & $-1.6 \pm 2.7$ & 0.001 \\
\hline
\end{tabular}

Notes: Data is shown as mean \pm SD. *Patients with $\mathrm{HbA}_{\mathrm{lc}}$ levels $<9.0 \%$ were instructed to follow a less strict carbohydrate restriction, while those with $\mathrm{HbA}$ lc levels $\geq 9.0 \%$ were instructed to follow a strict carbohydrate restriction; ${ }^{\dagger} P$ between patients on less strict CARD and patients on strict CARD. The parameter change $(\Delta)$ for each biomarker was defined as the level after 12 months minus the level at baseline. Abbreviations: BMI, body mass index; HOMA-IR, homeostasis model of assessment of insulin resistance; CARD, carbohydrate-reduced diet; SD, standard deviation.

Additionally, in the macroalbuminuric patients, the UAE was significantly reduced by $41 \%(95 \% \mathrm{CI}: 18,57)$ over the 1 -year period $(P=0.025)$ (Table 4$)$. Two of the six patients achieved remission to microalbuminuria (Figure 1).

In the microalbuminuric patients, the values for BMI, FPG, $\mathrm{HbA}_{1 \mathrm{c}}$, IRI, HOMA-IR, serum HDL cholesterol, and systolic BP significantly decreased (Table 4). The eGFR did not significantly decrease.

\section{Correlation of $\triangle \%$ UAE with changes in cardiovascular risk factors in microalbuminuric patients}

The $\Delta \%$ UAE was significantly and positively correlated with $\Delta$ HOMA-IR levels $\left(\mathrm{r}_{\mathrm{s}}=0.308 ; P=0.031\right)$ (Figure 2)
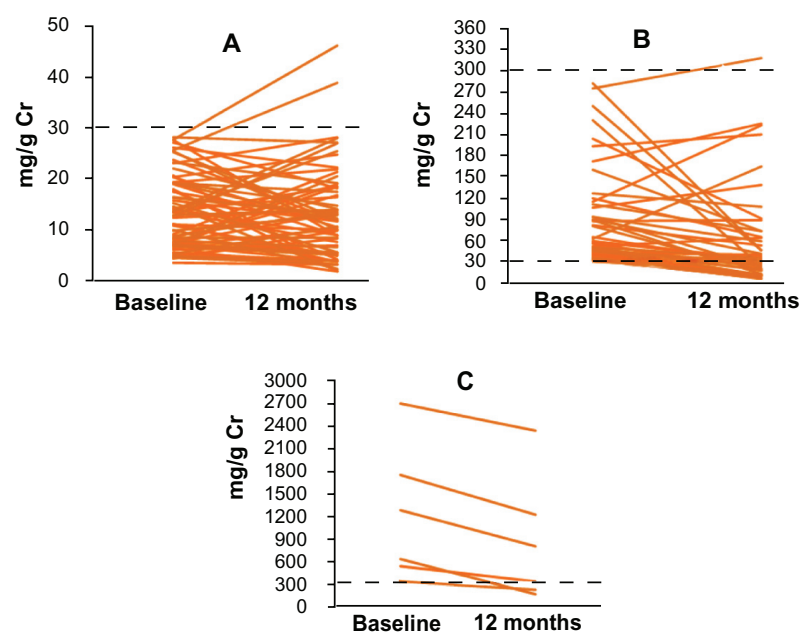

Figure I Individual changes in UAE ( $\mathrm{mg} / \mathrm{g} \mathrm{Cr}$ ) in $(\mathbf{A})$ normoalbuminuric patients $(n=68),(B)$ microalbuminuric patients $(n=50)$, and $(C)$ macroalbuminuric patients $(n=6)$, over 12 months. Dot lines show borderlines between normoalbuminuria and microalbuminuria (30 mg/g $\mathbf{C r})$ in $(\mathbf{A}$ and $\mathbf{B})$, and between microalbuminuria and macroalbuminuria (300 $\mathrm{mg} / \mathrm{g} \mathrm{Cr}$ ) in (B and $\mathbf{C})$.

Abbreviations: $\mathrm{Cr}$, creatinine; UAE, urinary albumin secretion.

but not correlated with changes in the other clinical variables. Moreover, the $\Delta \%$ UAE was significantly and inversely correlated with baseline HOMA-IR levels $\left(\mathrm{r}_{\mathrm{s}}=-0.367 ; P=0.009\right)$ and IRI levels $\left(\mathrm{r}_{\mathrm{s}}=-0.349\right.$; $P=0.013$ ). The $\triangle$ HOMA-IR levels were strongly and inversely correlated with the baseline HOMA-IR levels $\left(\mathrm{r}_{\mathrm{s}}=-0.687 ; P<0.001\right)$.

\section{Discussion}

In this study, remission (52\%) and a remarkable reduction (53\%) in UAE were achieved with the consumption of a moderate LCD for 12 months by microalbuminuric outpatients with T2DM. Even when patients taking olmesartan were excluded from consideration, the UAE was significantly decreased by $41 \%$. This reduction in UAE was significantly and positively correlated with a reduction in HOMA-IR levels.

These findings must be interpreted with caution because of the relatively small number of patients and the lack of control subjects treated with an HCD. Thus, findings could result in part from improved lifestyle and compliance to medication protocols. However, the analysis that excluded patients taking metformin during the study period did not materially change the findings and only two patients increased their physical activity levels.

"CARD" is defined as a moderate LCD (26\% to $45 \%$ carbohydrate), as opposed to a $\mathrm{LCD}(<26 \%$ carbohydrate $){ }^{24}$ In this study, one principle of CARD was to adopt the proper method of carbohydrate restriction according to a 
Table 4 Changes in UAE, BMI, glycemic control, fasting serum insulin, serum lipid profiles, blood pressure, and eGFR over 12 months

\begin{tabular}{|c|c|c|c|c|c|c|}
\hline & $\begin{array}{l}\text { Normoalbuminuria } \\
(n=68)\end{array}$ & $P^{*}$ & $\begin{array}{l}\text { Microalbuminuria } \\
(n=50)\end{array}$ & $P^{*}$ & $\begin{array}{l}\text { Macroalbuminuria } \\
(\mathrm{n}=6)\end{array}$ & $P^{*}$ \\
\hline$\Delta \%$ UAE (\%) $(95 \% \mathrm{Cl})^{\dagger}$ & $-20(-33,-4)$ & $0.02 I^{\ddagger}$ & $-53(-62,-43)$ & $<0.00 \mathrm{I}^{\ddagger}$ & $-4 \mid(-57,-18)$ & $0.025^{\ddagger}$ \\
\hline$\Delta$ body mass index & $-0.9 \pm 1.3$ & $<0.001$ & $-0.6 \pm 1.3$ & 0.003 & $-0.6 \pm 0.4$ & 0.028 \\
\hline $\begin{array}{l}\Delta \text { fasting plasma glucose } \\
(\mathrm{mg} / \mathrm{dL})\end{array}$ & $-13 \pm 37$ & 0.003 & $-29 \pm 48$ & $<0.001$ & $-47 \pm 63$ & 0.116 \\
\hline$\Delta$ hemoglobin $\mathrm{A}_{\mathrm{lc}}(\%)$ & $-1.2 \pm 1.2$ & $<0.001$ & $-1.4 \pm 1.5$ & $<0.001$ & $-1.8 \pm 2.5$ & 0.074 \\
\hline $\begin{array}{l}\Delta \text { fasting serum insulin } \\
(\mathrm{IU} / \mathrm{mL})\end{array}$ & $-1.0 \pm 4.4$ & 0.008 & $-0.9 \pm 3.4$ & 0.049 & $1.5 \pm 2.3$ & 0.115 \\
\hline$\Delta \mathrm{HOMA}-\mathrm{IR}$ & $-0.52 \pm 1.9$ & 0.001 & $-0.9 \pm 1.4$ & $<0.001$ & $-0.03 \pm 0.7$ & 0.753 \\
\hline$\Delta$ LDL-cholesterol $(\mathrm{mg} / \mathrm{dL})^{\S}$ & $-6 \pm 26$ & 0.089 & $-3 \pm 31$ & 0.695 & $-11,-7$ & \\
\hline$\Delta \mathrm{HDL}-$ cholesterol $(\mathrm{mg} / \mathrm{dL})^{\S}$ & $5 \pm 13$ & 0.016 & $6 \pm 11$ & 0.008 & $0,-7$ & \\
\hline$\Delta$ triglycerides $(\mathrm{mg} / \mathrm{dL})^{\S}$ & $-11 \pm 58$ & 0.297 & $-30 \pm 136$ & 0.432 & 35,89 & \\
\hline $\begin{array}{l}\Delta \text { systolic blood pressure } \\
(\mathrm{mmHg})\end{array}$ & $-4 \pm 12$ & 0.016 & $-7 \pm 16$ & 0.008 & $-11 \pm 22$ & 0.293 \\
\hline $\begin{array}{l}\Delta \text { diastolic blood pressure } \\
(\mathrm{mmHg})\end{array}$ & $-3 \pm 9$ & 0.016 & $-3 \pm 10$ & 0.084 & $-5 \pm 14$ & 0.916 \\
\hline$\Delta \mathrm{eGFR}\left(\mathrm{mL} / \mathrm{min} / \mathrm{l} .73 \mathrm{~m}^{2}\right)$ & $-0.0 \pm 10.7$ & 0.656 & $-2.9 \pm 11.9$ & 0.218 & $-12 \pm 16$ & 0.075 \\
\hline
\end{tabular}

Notes: Data is shown as mean \pm SD. *P Wilcoxon test between baseline and 12 months except for UAE; †geometric means; ${ }^{\dagger}$ paired $t$-test; ${ }^{5}$ patients who received anti-lipid drugs were excluded ( 18 for normoalbuminuria, 17 for microalbuminuria, and four for macroalbuminuria). The parameter change ( $\Delta$ ) was defined as the level after 12 months minus the level at baseline.

Abbreviations: UAE, urinary albumin excretion; BMI, body mass index; eGFR, estimated glomerular filtration rate; $\triangle \%$ UAE, percentage change in urinary albumin excretion; CI, confidence interval; HOMA-IR, homeostasis model of assessment of insulin resistance; LDL, low-density lipoprotein; HDL, high-density lipoprotein; SD, standard deviation.

patient's baseline $\mathrm{HbA}_{1 \mathrm{c}}$ level. ${ }^{14,15}$ This strategy resulted in different compositions of dietary macronutrients in the less strict CARD versus the strict CARD, with lower \%C (33\% carbohydrate) and higher $\% \mathrm{~F}$ ( $42 \%$ fat) in the strict $\mathrm{CARD}$, compared with the less strict CARD (40\% carbohydrate

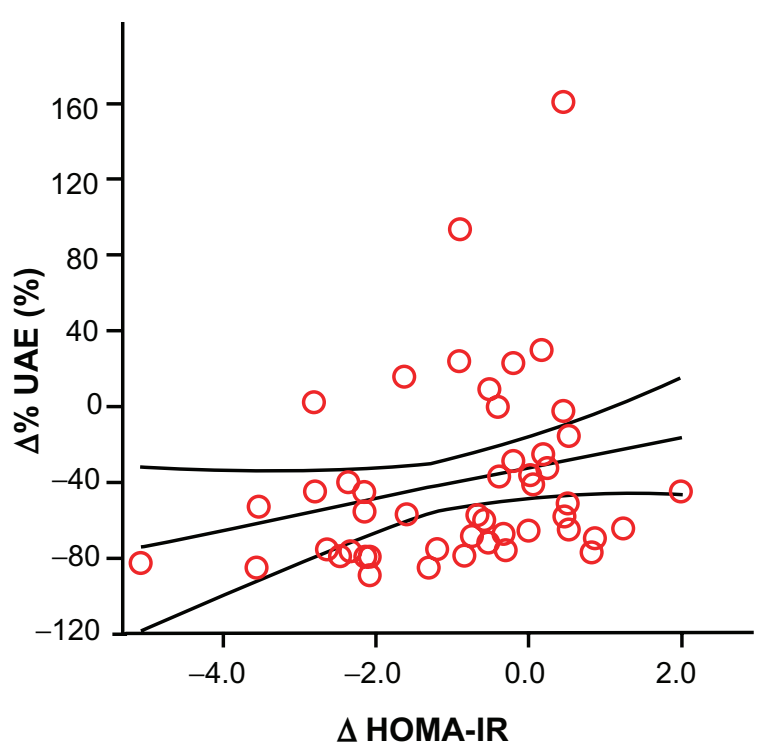

Figure 2 Correlation of $\triangle \%$ UAE with $\triangle$ HOMA-IR in the 50 microalbuminuric patients.

Notes: The figure shows the regression line and the $95 \%$ confidence interval, superimposed on the graph. The $\triangle \% \cup A E$ was significantly and positively correlated with $\triangle$ HOMA-IR levels $\left(r_{s}=0.308 ; P=0.031\right)$.

Abbreviations: $\triangle \% U A E$, percentage change in urinary albumin secretion; HOMA-IR, homeostasis model of assessment of insulin resistance. and $36 \%$ fat). The strict $\mathrm{CARD}$ regimen was associated with remarkable decreases in $\mathrm{HbA}_{1 \mathrm{c}}$ and HOMA-IR levels when compared with the less strict CARD regimen. Nevertheless, both CARD regimens achieved an $\mathrm{HbA}_{1 \mathrm{c}}$ level of $\leq 7.0 \%$ over 12 months despite different baseline $\mathrm{HbA}_{1 \mathrm{c}}$ levels; the strict and less strict CARDs improved glycemic control among patients with severe T2DM and those with mild T2DM, respectively.

Along with improvements in cardiovascular risk factors (primarily BMI, glycemic control, and HOMA-IR), a remarkable reduction in UAE was achieved with the consumption of CARD in microalbuminuric patients over 12 months. Our results suggest that moderate LCDs have the ability to reduce microalbuminuria; however, the strict CARD and less strict CARD had a similar level of effect on reducing UAE. To address this issue, further studies are needed to investigate the difference in patients' baseline \% (typically, a conventional calorie-restricted diet) and their $\% \mathrm{C}$ in the strict or the less strict CARD.

Insulin resistance is a critical factor in the development of T2DM and is closely related to hypertension, atherogenic dyslipidemia, and obesity, which often manifest concomitantly in the clinical context. ${ }^{25}$ The CARD achieved a significant reduction in HOMA-IR levels by 12 months in microalbuminuric patients and this reduction in insulin resistance may be associated with a reduction in UAE. Several cross-sectional studies have demonstrated that an 
increased UAE is related to higher insulin resistance as estimated by HOMA-IR levels. ${ }^{26,27}$ We demonstrated that the $\Delta \%$ UAE was positively correlated with $\Delta$ HOMA-IR levels, higher HOMA-IR levels at baseline were associated with greater reductions in UAE, and the $\triangle$ HOMA-IR levels were inversely correlated with baseline HOMA-IR levels in the microalbuminuric patients treated with CARD. In association with the marked decrease in HOMA-IR levels, UAE decreased more among microalbuminuric patients with higher HOMA-IR at baseline, probably because there is greater room for improvement in HOMA-IR levels over a 12-month period.

High-dose ARBs can reduce the level of microalbuminuria by $30 \%-48 \%$ over a period of $6-24$ months. ${ }^{4,22}$ Many studies have shown that the reduction in microalbuminuria caused by ARBs in patients with T2DM under high-carbohydrate conditions is independent of the BP-lowering effects of ARBs. ${ }^{4,7}$ In the current study, a moderate LCD without the use of ARBs achieved a $41 \%$ reduction in UAE over a 12 -month period among the microalbuminuric patients, which is equivalent to the efficacy of high-dose ARBs in T2DM patients under high-carbohydrate conditions. Moreover, the moderate LCD in combination with low-dose ARBs (olmesartan) reduced UAE by $64 \%$. Our results, together with the effects of high-dose ARBs on microalbuminuria, $4,7,28$ suggest that the combination therapy of moderate LCDs with the use of a higher dose of ARBs may have great potential for further reducing microalbuminuria.

In summary, a 53\% reduction in UAE was achieved with the consumption of a moderate LCD ( $38 \%$ carbohydrate) over a 12-month period in microalbuminuric patients with T2DM. When patients taking olmesartan were excluded from consideration, the UAE was decreased by $41 \%$. Moreover, $52 \%$ of these patients were in remission to normoalbuminuria at 12 months. The $\Delta \%$ UAE was positively correlated with $\triangle$ HOMA-IR in patients with microalbuminuria. These data suggest that moderate LCDs have the ability to reduce UAE in patients with T2DM. Our findings warrant a long-term and large-scale interventional study to confirm the effects of LCDs on reducing albuminuria.

\section{Authors' contributions}

$\mathrm{HH}$ and TS designed the study and participated in data collection. $\mathrm{HH}, \mathrm{KW}$, and HU performed the statistical analysis and interpreted the data. HH wrote the manuscript.

\section{Disclosure}

The authors declare no conflicts of interest in this work.

\section{References}

1. Bilous R. Microvascular disease: what does the UKPDS tell us about diabetic nephropathy? Diabet Med. 2008;25 Suppl 2:25-29.

2. Gross JL, de Azevedo MJ, Silveiro SP, Canani LH, Caramori ML, Zelmanovitz T. Diabetic nephropathy: diagnosis, prevention, and treatment. Diabetes Care. 2005;28(1):164-176.

3. American Diabetes Association. Standards of medical care in diabetes 2008. Diabetes Care. 2008;31 Suppl 1:S12-S54.

4. Basi S, Fesler P, Mimran A, Lewis JB. Microalbuminuria in type 2 diabetes and hypertension: a marker, treatment target, or innocent bystander? Diabetes Care. 2008;31(Suppl 2):S194-S201.

5. Araki S, Haneda M, Koya D, Kashiwagi A, Uzu T, Kikkawa R. Clinical impact of reducing microalbuminuria in patients with type 2 diabetes mellitus. Diabetes Res Clin Pract. 2008;82 Suppl 1:S54-S58.

6. Gaede P, Tarnow L, Vedel P, Parving HH, Pedersen O. Remission to normoalbuminuria during multifactorial treatment preserves kidney function in patients with type 2 diabetes and microalbuminuria. Nephrol Dial Transplant. 2004;19(11):2784-2788.

7. Casas JP, Chua W, Loukogeorgakis S, et al. Effect of inhibitors of the renin-angiotensin system and other antihypertensive drugs on renal outcomes: systematic review and meta-analysis. Lancet. 2005; 366(9502):2026-2033.

8. Westman EC, Yancy WS Jr, Mavropoulos JC, Marquart M, McDuffie JR. The effect of a low-carbohydrate, ketogenic diet versus a low-glycemic index diet on glycemic control in type 2 diabetes mellitus. Nutr Metab (Lond). 2008;5:36.

9. Accurso A, Bernstein RK, Dahlqvist A, et al. Dietary carbohydrate restriction in type 2 diabetes mellitus and metabolic syndrome: time for a critical appraisal. Nutr Metab (Lond). 2008;5:9.

10. Katan MB. Alternatives to low-fat diets. Am J Clin Nutr. 2006;83(5): 989-990.

11. Volek JS, Phinney SD, Forsythe CE, et al. Carbohydrate restriction has a more favorable impact on the metabolic syndrome than a low fat diet. Lipids. 2009;44(4):297-309.

12. Tada N, Maruyama C, Koba S, et al. Japanese dietary lifestyle and cardiovascular disease. J Atheroscler Thromb. 2011;18(9):723-734.

13. Oza-Frank R, Cheng YJ, Narayan KM, Gregg EW. Trends in nutrient intake among adults with diabetes in the United States: 1988-2004. J Am Diet Assoc. 2009;109(7):1173-1178.

14. Haimoto H, Iwata M, Wakai K, Umegaki H. Long-term effects of a diet loosely restricting carbohydrates on $\mathrm{HbA}_{1 \mathrm{c}}$ levels, $\mathrm{BMI}$ and tapering of sulfonylureas in type 2 diabetes: a 2-year follow-up study. Diabetes Res Clin Pract. 2008;79(2):350-356.

15. Haimoto H, Sasakabe T, Wakai K, Umegaki H. Effects of a lowcarbohydrate diet on glycemic control in outpatients with severe type 2 diabetes. Nutr Metab (Lond). 2009;6:21.

16. Sasakabe T, Haimoto H, Umegaki H, Wakai K. Effects of a moderate low-carbohydrate diet on preferential abdominal fat loss and cardiovascular risk factors in patients with type 2 diabetes. Diabetes Metab Syndr Obes. 2011;4:167-174.

17. Hu FB. Are refined carbohydrates worse than saturated fat? Am J Clin Nutr. 2010;91(6):1541-1542.

18. Fung TT, van Dam RM, Hankinson SE, Stampfer M, Willett WC, Hu FB. Low-carbohydrate diets and all-cause and cause-specific mortality: two cohort studies. Ann Intern Med. 2010;153(5):289-298.

19. Tanaka K, Moriya T, Kanamori A, Yajima Y. Analysis and a long-term follow up of ketosis-onset Japanese NIDDM patients. Diabetes Res Clin Pract. 1999;44(2):137-146.

20. Weidmann P, Schneider M, Böhlen L. Therapeutic efficacy of different antihypertensive drugs in human diabetic nephropathy: an updated meta-analysis. Nephrol Dial Transplant. 1995;10 Suppl 9:S39-S45.

21. Ruilope LM, Segura J. Kidney protection: a key target in the management of patients with diabetes. J Hypertens Suppl. 2009;27(1):S15-S18.

22. Muniyappa R, Lee S, Chen H, Quon MJ. Current approaches for assessing insulin sensitivity and resistance in vivo: advantages, limitations, and appropriate usage. Am J Physiol Endocrinol Metab. 2008; 294(1):E15-E26. 
23. Matsuo S, Imai E, Horio M, et al; for Collaborators developing the Japanese equation for estimated GFR. Revised equations for estimated GFR from serum creatinine in Japan. Am J Kidney Dis. 2009;53(6): 982-992.

24. Feinman RD. Fad diets in the treatment of diabetes. Curr Diab Rep. 2011;11(2):128-135.

25. Chapman MJ, Sposito AC. Hypertension and dyslipidaemia in obesity and insulin resistance: pathophysiology, impact on atherosclerotic disease and pharmacotherapy. Pharmacol Ther. 2008;117(3):354-373.

26. Esteghamati A, AshrafH, Nakhjavani M, Najafian B, Hamidi S, Abbasi M. Insulin resistance is an independent correlate of increased urine albumin excretion: a cross-sectional study in Iranian Type 2 diabetic patients. Diabet Med. 2009;26(2):177-181.
27. De Cosmo S, Minenna A, Ludovico O, et al. Increased urinary albumin excretion, insulin resistance, and related cardiovascular risk factors in patients with type 2 diabetes: evidence of a sex-specific association. Diabetes Care. 2005;28(4):910-915.

28. Ikeda H, Hamamoto Y, Honjo S, Nabe K, Wada Y, Koshiyama H. Olmesartan reduced microalbuminuria in Japanese subjects with type 2 diabetes. Diabetes Res Clin Pract. 2009;83(1):117-118.

\section{Publish your work in this journal}

Diabetes, Metabolic Syndrome and Obesity: Targets and Therapy is an international, peer-reviewed open-access journal committed to the rapid publication of the latest laboratory and clinical findings in the fields of diabetes, metabolic syndrome and obesity research Original research, review, case reports, hypothesis formation, expert opinion and commentaries are all considered for publication. The manuscript management system is completely online and includes a very quick and fair peer-review system, which is all easy to use. Visit http://www.dovepress.com/testimonials.php to read real quotes from published authors.

Submit your manuscript here: http://www.dovepress.com/diabetes-metabolic-syndrome-and-obesity-targets-and-therapy-journal 